\title{
Corneal topographic changes after 20-gauge pars plana vitrectomy associated with scleral buckling for the treatment of rhegmatogenous retinal detachment
}

\author{
Alterações topográficas da córnea após vitrectomia via \\ pars plana 20-gauge associada à introflexão escleral \\ para o tratamento do descolamento de retina regmatogênico
}

Alexandre Achille Grandinetti ${ }^{1}$, Janaína Dias ${ }^{2}$, Ana Carolina Trautwein ${ }^{3}$, Natasha Iskorostenski ${ }^{3}$, Luciane Moreira ${ }^{4}$, Ana Tereza Ramos Moreira ${ }^{4}$

\begin{abstract}
Purpose:To evaluate the changes in corneal topography after 20-gauge pars plana vitrectomy associated with scleral buckling for the repair of rhegmatogenous retinal detachment. Methods: Twenty-five eyes of 25 patients with rhegmatogenous retinal detachment were included in this study. 20-gauge pars plana vitrectomy associated with scleral buckling was performed in all patients. The corneal topography of each was measured before surgery and one week, one month, and three months after surgery by computer-assisted videokeratoscopy.Results: A statistically significant central corneal steepening (average, $0,9 \mathrm{D}, p<0,001$ ) was noted one week after surgery. The total corneal astigmatism had a significant increase in the first postoperative month $(p=0,007)$. All these topographic changes persisted for the first month but returned to preoperative values three months after the surgery. Conclusion:Pars plana vitrectomy with scleral buckling was found to induce transient changes in corneal topography.
\end{abstract}

Keywords:Retina; Cornea; Retinal detachment; Scleral buckling; Vitrectomy

ClinicalTrials.gov Identifier: NCTO1446367

\section{RESUMO}

Objetivo:Avaliar as alterações topográficas da córnea após a realização de vitrectomia via pars plana 20-gauge associada à introflexão escleral para o tratamento do descolamento de retina regmatogênico.Métodos: Vinte e cinco pacientes com descolamento de retina regmatogênico foram incluídos neste estudo. Vitrectomia via pars plana 20-gauge associada à introflexão escleral foi realizada em todos os pacientes. O exame de topografia de córnea computadorizada de cada paciente foi realizado antes da cirurgia e ao sétimo dia, trigésimo dia e três meses após a cirurgia. Resultados: Um aumento da curvatura corneana estatisticamente significativo foi encontrado no sétimo dia após a cirurgia (média $0,9 \mathrm{D}, \mathrm{p}<0,001$ ). $\mathrm{O}$ astigmatismo corneano total teve um aumento significativo no primeiro mês pós-operatório $(\mathrm{p}=0,007)$.Todas as alterações topográficas persistiram no primeiro mês pós-operatório, mas retornaram aos valores pré-operatórios três meses após a cirurgia.Conclusão: A vitrectomia via pars plana associada à introflexão escleral pode induzir alterações transitórias na topografia corneana.

Descritores: Retina; Córnea; Descolamento retiniano; Recurvamento da esclera; Vitrectomia

Identificador ClinicalTrials.gov : NCTO1446367

\footnotetext{
'Retina and pterígeos Vitreo, Hospital de Clínicas da Universidade Federal do Paraná (UFPR) - Curitiba (PR), Brazil; ${ }^{2}$ Hospital Universitário Evangélico de Curitiba - Curitiba (PR), Brazil;

${ }^{3}$ Universidade Federal do Paraná (UFPR) - Curitiba (PR), Brazil;

${ }^{4}$ Professor of Ophthalmology, Universidade Federal do Paraná (UFPR) - Curitiba (PR), Brazil.

$10^{\text {th }}$ Euretina Meeting, 2-5 september 2010, Paris, France - Universidade Federal do Paraná (UFPR) - Curitiba (PR), Brazil
}

The authors declare no conflicts of interest

Recebido para publicação em: 21/11/2011 - Aceito para publicação em: 7/3/2012 


\section{INTRODUCTION}

$\mathbf{T}$ The treatment of rhegmatogenous retinal detachments and it complications continue to be one of the most important indications for vitreoretinal surgery, being a well-known cause of ocular refractive changes. The use of an encircling band creates an indentation of the eye that increases the anteroposterior axial length and can change the corneal shape ${ }^{(1,2)}$. A myopic shift or lowering hypermetropia and irregular corneal astigmatism owing to the explants can be found ${ }^{(3)}$. More recently, with the advent of small gauge transconjunctival vitrectomy, the effects of the vitrectomy surgery on the cornea have been compared when using different techniques ${ }^{(4)}$. Some studies have evaluated corneal changes after pars plana vitrectomy and scleral buckling surgery, and although some studies found statistically significant corneal shape changes ${ }^{(5,6)}$, others found no significant changes ${ }^{(7)}$.

Current techniques of rhegmatogenous retinal detachment repair allow most detachments to be repaired successfully. However, even after successful retinal reattachment, postoperative vision may be unsatisfactory for the patient in some cases due to severe myopia or astigmatism that might persist after surgery ${ }^{(8)}$.

The cornea's refracting surface is responsible for about two thirds of the refractive power of the eye and plays an important role in focusing images on the retina. This function can be defined in terms of corneal shape, regularity, clarity and the refractive index ${ }^{(5)}$, all of which might be susceptible to intraoperative compromise after vitreoretinal surgery.

In this study, we investigated the possible corneal changes after 20-gauge pars plana vitrectomy (PPV) associated with scleral buckling for the treatment of rhegmatogenous retinal detachment using computer-assisted videokeratography.

\section{Methods}

Twenty-five patients with rhegmatogenous retinal detachment who underwent 20-gaugePPV combined with scleral buckling were prospectively included in this study. Approval from the appropriate ethics committee was obtained, and informed consent was acquired from all patients before surgery.

Patients with a history of corneal changes prior to surgery (rigid contact lens use, refractive surgery, cataract surgery, corneal trauma, corneal transplant, keratoconus, corneal ulcers) and other causes of retinal detachment (proliferative diabetic retinopathy, tractional, traumatic, associated with tumors of the choroid, and inflammation, among others) were excluded from the study. All surgeries were planned and performed by the same surgeon successfully (AAG).

All patients underwent a 20-gauge PPV combined with scleral buckling, which consisted on the placement of a infusion cannula $4 \mathrm{~mm}$ from the corneal limbus in the inferior temporal quadrant between the insertions of the rectus muscles, and two sclerotomies $4 \mathrm{~mm}$ from the corneal limbus in the upper quadrants, always located at the top of the line of the rectus muscles insertion. Total vitrectomy was performed, demarcation of the tears with endodiatermy, drainage of subretinal fluid followed by endolaser photocoagulation around the retinal tears. Scleral buckling technique was performed using a silicone band number 42 (Labtician S2971; Labtician Ophthalmic Inc, Canada), which was sutured in the 4 quadrants at a distance of $11 \mathrm{~mm}$ from the corneal limbus, using Mersilene 5.0 sutures to hold the band in the middle of the quadrant. After the surgery was performed, the vitreous cavity substitute was chosen according to the discretion of the surgeon (perfluoropropane gas or silicone oil) and the sclerotomies and conjunctiva were closed using 7.0 vicryl sutures.

Twenty-five eyes of these 25 patients were analyzed using computerized videokeratography (EyeSys 2000; Corneal Analysis System v4.0). Corneal topography was measured before surgery, as well as one week, one month and three months after surgery. At least three videokeratographs were recorded from each patient, and the data were obtained from the best quality keratograph. The analysis of the corneal videokeratographs was based on the Holladay Diagnostic Summary (HDS) software package. The HDS gives four color-coded maps and 15 corneal parameters. The maps include two refractive power maps on standard and auto scales, a profile difference map for determining the corneal shape, and a distortion map that provides information about the visual performance and optical quality of the cornea. The parameters from the HDS provide information of the central $3 \mathrm{~mm}$ of the cornea. It should be noted that optical distortions outside this $3.0 \mathrm{~mm}$ pupil zone are shown to have little effect on the visual performance except when the pupil is dilated.

In this study, steep refractive power, flat refractive power, and total astigmatism parameters from the HDS were used to investigate the changes in corneal topography. The steep refractive power (K2) is the strongest refractive power in the central cornea, whereas the flat refractive power (K1) is the weakest refractive power. The difference between these two parameters is defined as the total astigmatism of the cornea.

\section{Results}

Of the twenty-five patients included in this study, 15 (60\%) were male and $10(40 \%)$ were female. The left eye was affected in 14 patients $(56 \%)$ and the right eye in 11 patients $(44 \%)$.

The mean age ofthe patients admitted to surgeries was 54.52 years, the youngest being 28 -year-old and the oldest 68 year-old.

The assessment of the macula in the preoperative period was defined as attached in 6 cases (24\%) and detached in 19 cases $(76 \%)$.

The vitreous substitute most commonly used was perfluoropropane gas $(\mathrm{C} 3 \mathrm{~F} 8)$, in 19 patients $(72 \%)$, and silicone oil in 7 cases $(28 \%)$.

After surgery, an average of a 0,9 diopter (D) increase in central corneal steepening, was detected in the first week. The difference was statistically significant when compared with preoperative values $(p<0.001)$. Figures $1 \mathrm{~A}$ and B illustrate the postoperative change in a patient with marked steepening of the central cornea in the first week. This central steepening started to decrease gradually throughout the first month after surgery and came close to preoperative values at three months. The flat refractive power (K1) increased on an average of $0,6 \mathrm{D}$ in the first week after surgery. The difference was statistically significant when compared with preoperative values $(p<0.05)$. There was no residual central corneal flattening at the three-month visit compared with preoperative values. All these changes are listed in table 1 .

Total corneal astigmatism before surgery was found to be mean $0,78 \mathrm{D}$. It reached its highest level in the first postoperative week (mean, 1,14 D). This difference was statistically significant $(\mathrm{p}<0,005)$. The corneal astigmatism slightly decreased and was a mean of $1,06 \mathrm{D}$ by the first postoperative month. The induced corneal astigmatism was a mean of $0,89 \mathrm{D}$ at the three month visit, and no statistically significant difference was seen by that time when compared to the preoperative values. The changes in total corneal astigmatism are listed in table 2. 

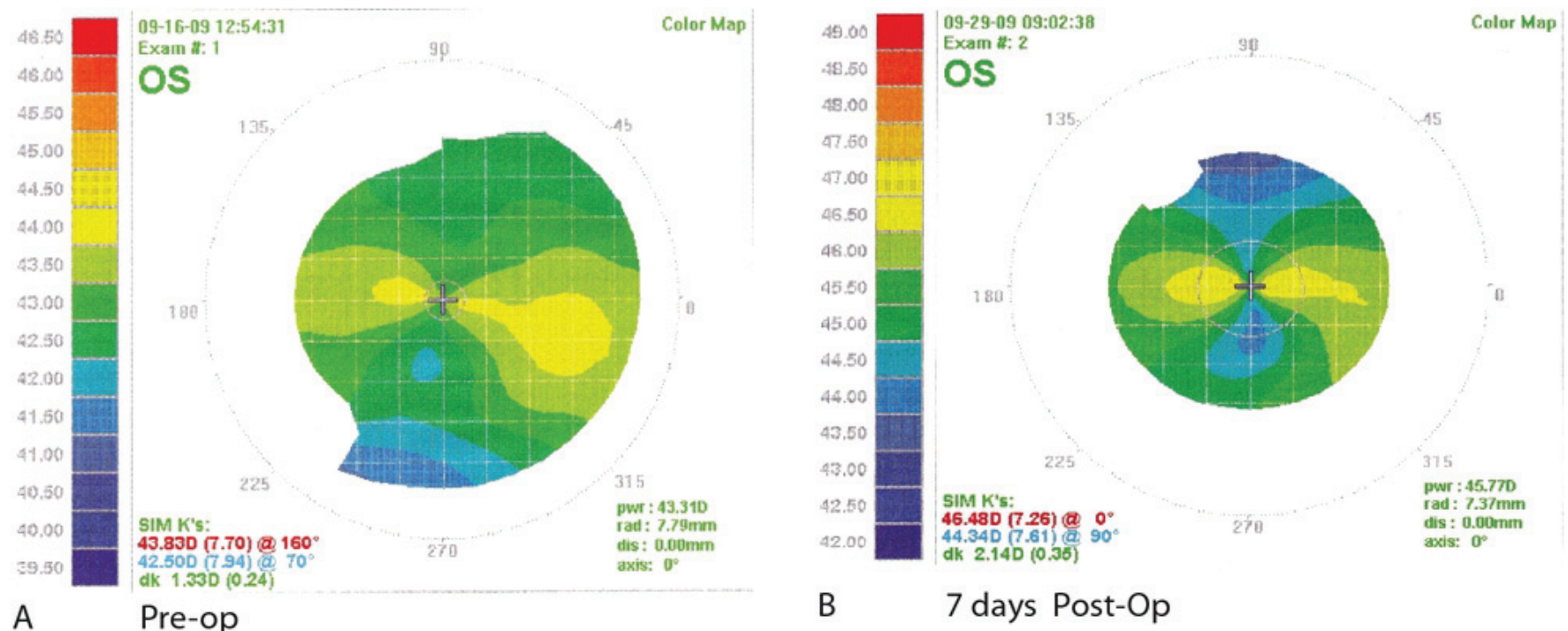

A Pre-op

Figure 1:A) Corneal videokeratography of a patient before PPV with scleral buckling; B) note the central corneal steepening seven days after surgery

Table 1

\section{Changes in corneal steepening and flattening after surgery}

\begin{tabular}{lcccc}
\hline & $\begin{array}{l}\text { Before } \\
\text { surgery }\end{array}$ & $\mathbf{1}^{\text {st }}$ week & $\mathbf{1}^{\text {st }}$ month & $\mathbf{3}^{\text {rd }}$ month \\
\hline Central steepening & & & & \\
Mean & 42.4 & 43.3 & 43.3 & 42.5 \\
\pm SD & 1.7 & 2.0 & 2.1 & 1.7 \\
p & & $<0.001^{\mathrm{a}}$ & $<0.001^{\mathrm{a}}$ & $0.504^{\mathrm{a}}$ \\
Central flattening & & & & \\
Mean & 41.6 & 42.2 & 42.2 & 41.6 \\
\pm SD & 1.5 & 1.8 & 1.9 & 1.7 \\
p-value & & $<0.05^{\mathrm{a}}$ & $<0.05^{\mathrm{a}}$ & $0.747^{\mathrm{a}}$ \\
\hline
\end{tabular}

${ }^{\text {a }}$ Compared with preoperative values / All values are in diopters

Table 2

Changes in corneal total astigmatism after surgery

\begin{tabular}{lcccc}
\hline & $\begin{array}{c}\text { Before } \\
\text { surgery }\end{array}$ & $\mathbf{1}^{\text {st }}$ week & $\mathbf{1}^{\text {st }}$ month & $3^{\text {rd }}$ month \\
\hline $\begin{array}{l}\text { Total astigmatism } \\
\text { Mean }\end{array}$ & 0.78 & 1.14 & 1.06 & 0.89 \\
\pm SD & 0.72 & 0.78 & 0.61 & 0.61 \\
p-value & & $<0.05^{\text {a }}$ & $<0.05^{\text {a }}$ & $0.441^{\text {a }}$ \\
\hline
\end{tabular}

${ }^{\text {a }}$ Compared with preoperative values / All values are in diopters

\section{Discussion}

It is well known that changes in the corneal shape and refractive status induced by scleral buckling may occur soon after surgery. These changes include postoperative corneal astigmatism, particularly steepening and flattening of the cornea, and a myopic shift( ${ }^{(4)}$.
We analyzed the central corneal topographic changes that occur after vitrectomy surgery with scleral buckling, for the treatment of rhegmatogenous retinal detachment with the use of videokeratography.

In the current study, we found a significant central corneal steepening in the first week postoperatively, which persisted during the first 30 days after surgery and regressed to preoperative values three months after surgery. Hayashi et al. ${ }^{(9)}$, who have used videokeratography after scleral buckling surgery, reported increased postoperative central corneal steepening and peripheral corneal flattening. Weinberger et al. ${ }^{(3)}$, also found central corneal steepening after scleral buckling that lasted for as long as 3 months. It is assumed that, the scleral buckle indents the eye circumferentially and causes corneal steepening and corneal flattening postoperatively.

The corneal contour isknown to be altered after PPV and scleral buckling. Domniz et al. ${ }^{(5)}$, measured the corneal topography in eyes undergoing PPV by means of videokeratography and reported that the corneal surface cylinder, average corneal power, regularity index , surface asymmetry index and irregular astigmatism index were increased at two days and one week after surgery and returned to its baseline onemonth after surgery. Similarly, Avitabile et al. ${ }^{(4)}$ described a transient increase of keratometric astigmatism 1 week after PPV when comparing 20 -gauge and 25-gauge techniques, and that it returned to the preoperative levelone month after surgery on the 25 -gauge group and 2 months after surgery on the 20 -gauge group. The differences between the two groups were thought to happen due to different durations for complete scleral healing, loosening of the sutures and the use of scleral cautery on the 20-gauge group.

Our findings are consistent with previous reports. However, the amount of astigmatic changes in this study was $0.36 \mathrm{D}$ at one week postoperatively, which is much smaller than a range of 1.5 to $3.0 \mathrm{D}$, at two to seven days after surgery reported previously. In our study, all patients were submitted to 20-gauge PPV combined with scleral buckling so that we had effects from both techniques inducing steepening of the cornea on different meridians, which could explain such results. Tear film dynamics affecting corneal topography may also be relevant to the differences between our results and those of previous studies ${ }^{(8)}$. 
We concluded that 20-gauge PPV associated with scleral buckling for the treatment of rhegmatogenous retinal detachment induces transient changes in the corneal topography causing corneal astigmatism, and that videokeratography is helpful for documenting such corneal changes after vitreoretinal surgery.

\section{REFERENCES}

1. Okada Y,Nakamura S, Kubo E, Oishi N,Takahashi Y,Akagi Y.Analysis of changes in corneal shape and refraction following scleral buckling surgery.Jpn J Ophthalmol. 2000;44(2):132-8.

2. Heimann H, Bartz-Schmidt KU, Bornfeld N, Weiss C, Hilgers RD, Foerster MH; Scleral BucklingversusPrimaryVitrectomy in RhegmatogenousRetinal DetachmentStudy Group. Scleral buckling versus primary vitrectomy in rhegmatogenous retinal detachment: a prospective randomized multicenter clinical study.Ophthalmology. 2007;114(12):2142-54

3. Weinberger D, Lichter H, Loya N, Axer-Siegel R, Muzmacher L, Gabbay U,Yassur Y. Corneal topographic changes after retinal and vitreous surgery.Ophthalmology. 1999;106(8):1521-4.

4. Avitabile T, Castiglione F, Bonfiglio V, Castiglione F. Transconjunctival sutureless 25 -gauge versus 20 -gauge standard vitrectomy: correlation between corneal topography and ultrasound biomicroscopy measurements of sclerotomy sites. Cornea. 2010;29(1):19-25
5. Domniz YY, Cahana M, Avni I. Corneal surface changes after pars plana vitrectomy and scleral buckling surgery.J Cataract Refract Surg. 2001;27(6):868-72.

6. Smiddy WE, Loupe DN, Michels RG, Enger C, Glaser BM, deBustros S. Refractive changes after scleral buckling surgery.Arch Ophthalmol. 1989;107(10):1469-71.

7. Goel R, Crewdson J, Chignell AH. Astigmatism following retinal detachment surgery. Br J Ophthalmol.1983;67(5):327-9.

8. Okamoto F, Okamoto C, Sakata N,Hiratsuka K, Yamane N,Hiraoka T, et al. Changes in corneal topography after 25 -gauge transconjunctival sutureless vitrectomy versus after 20-gauge standard vitrectomy.Ophthalmology. 2007;114(12):2138-41

9. Hayashi H, Hayashi K, Nakao F, Hayashi F. Corneal shape changes after scleral buckling surgery.Ophthalmology. 1997;104(5):831-7.

\section{Autor correspondente:}

Alexandre Achille Grandinetti, MD

Av. Vicente Machado, no 1171 - Curitiba (PR) - Brazil

Postal Code 80420-011

Phone/Fax: (55) 41 3323-1120

E-mail: alexandregrandinetti@gmail.com 